\title{
Utility of albumin to creatinine ratio in screening for microalbuminuria among newly diagnosed diabetic patients in Uganda: a cross sectional study
}

\author{
Martin Muddu ${ }^{1}$, Edrisa Mutebi ${ }^{1}$, Isaac Ssinabulya ${ }^{1}$, Samuel Kizito ${ }^{2}$, \\ Frank Mulindwa ${ }^{1}$, Charles Mondo Kiiza ${ }^{1}$
}

1. Department of Medicine Makerere University College of Health Sciences, Mulago Hospital Complex.

2. Clinical Epidemiology Unit, Makerere University College of Health Sciences.

\section{Emails:}

muddu.martin@gmail.com, mutebiedrisa@yahoo.com, ssinabulyaisaac@gmail.com, somekizito@yahoo.com, mulindwafrank93@gmail.com, charlesmondo2011@gmail.com

\begin{abstract}
:
Background: The aim of this study was to determine the prevalence and factors associated with microalbuminuria among newly diagnosed diabetic patients in Mulago National Referral Hospital, Uganda.

Methods: In this cross-sectional study conducted between June 2014 and January 2015, we collected information on patients' socio-demographics, biophysical profile, blood pressure, biochemical testing and echocardiographic findings using a pre-tested questionnaire. Bivariate and multivariate logistic regression analyses were used to investigate the association of several factors with microalbuminuria.

Results: Of the 175 patients recruited, males were $90(51.4 \%)$ and the mean age was $46 \pm 15$ years. Majority of patients had type

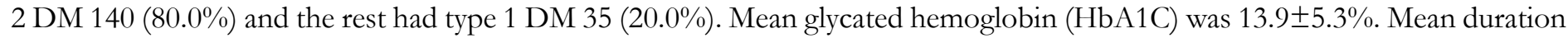
of diabetes was 2 months. Prevalence of microalbuminuria was $47.4 \%$ (95\% CI: 40.0\%-54.9\%) overall. Pregnancy was associated with microalbuminuria (OR7.74[95\%CI.1.01-76.47] P=0.050) while mild and moderate physical activity at work were inversely associated with microalbuminuria respectively (OR0.08[95\%CI0.01-0.95] P=0.046) and (OR0.07[95\%CI0.01-0.77] P=0.030). Conclusion: Prevalence of microalbuminuria was high in this group. Physical activity at work may be protective against microalbuminuria and this calls for longitudinal studies. Early detection and management of microalbuminuria in diabetics may slow progression to overt diabetic nephropathy (DN).
\end{abstract}

Keywords: Albumin, creatinine, microalbuminuria, diabetic patients, Uganda.

DOI: https://dx.doi.org/10.4314/ahs.v19i1.36

Cite as: Muddu M, Mutebi E, Ssinabulya I, Kizito S, Mulindwa F, CM K. Utility of albumin to creatinine ratio in screening for microalbuminuria among newly diagnosed diabetic patients in Uganda: a cross sectional study. Afri Health Sci. 2019;19(1). 1607-1616. bttps://dx.doi. org/10.4314/ahs.v19i1.36

\section{Background}

Microalbuminuria is an early marker of nephropathy, cardiovascular diseases and severe ocular morbidity in adults with diabetes ${ }^{1-5}$. It is a sub-clinical condition that is asso-

\section{Corresponding author: \\ Martin Muddu, Department of Medicine, Makerere University College of Health Sciences, Mulago Hospital Complex. \\ Email: muddu.martin@gmail.com}

ciated with high morbidity and mortality ${ }^{5,6}$. DM is one of the leading causes of microalbuminuria in $\mathrm{SSA}^{5,7,8}$.

The presence of microalbuminuria precedes the development of overt diabetic nephropathy by 10-14 years. It is at this stage that one can reverse diabetic nephropathy or prevent its progression ${ }^{5,8-10}$. Unfortunately, tests to detect microalbuminuria in diabetics are not routinely done in Uganda and sub-Saharan Africa (SSA) as a whole.

Among persons with DM, microalbuminuria has been estimated to be twice the prevalence in the general population in Africa ${ }^{5,11,12}$. Approximately half the patients with microalbuminuria will progress to overt proteinuria over 
the next decade ${ }^{6,13}$. Therefore, early detection and appropriate interventions in asymptomatic individuals may help in preventing deterioration in renal function, progression to diabetic nephropathy and ESRD 5 .

Therapeutic interventions which reverse microalbuminuria include intensified glycemic control, use of Angiotensin Converting Enzyme (ACE) inhibitors and these should be initiated in diabetics with microalbuminuria to prevent progress to overt diabetic nephropathy ${ }^{12}$.

$\mathbf{D N}$, the end result of microalbuminuria, is a major cause of morbidity, premature mortality, end stage renal disease, need for renal replacement therapy, cardiovascular diseases, and escalating health-care costs in diabetic patients ${ }^{6,12,14-18}$. The prevalence of DN is increasing steeply along with the diabetes epidemic ${ }^{15}$. Approximately one third to half of patients with diabetes develops renal manifestations ${ }^{14,15,19}$.

DN may be more frequent among patients in Africa as compared to those in the developed world due to delayed diagnosis, limited screening and diagnostic resources, poor glycemic control and inadequate treatment of microalbuminuria ${ }^{14,19,20}$.

From studies in the western world, the factors associated with microalbuminuria have been elucidated. ${ }^{5,6,12}$. In Afri$\mathrm{ca}$, there is paucity of data on the prevalence and factors associated with of microalbuminuria among diabetic patients $^{5,14}$.

Therefore this study sought to determine the prevalence and factors associated with microalbuminuria among newly diagnosed diabetic patients at Mulago National Referral Hospital in Uganda.

\section{Methods}

\section{Study design and participants}

This was a cross-sectional study among 175 newly diagnosed diabetic patients at Mulago National referral hospital in Uganda conducted between June 2014 and January 2015. DM was diagnosed using the standard criteria of fasting blood sugar of $\geq 6.9 \mathrm{mmol} / \mathrm{L}$. All newly diagnosed diabetic patients aged 18 years and above attending the diabetic clinic or admitted to the medical wards of Mulago hospital during the study period who met the inclusion criteria and provided informed consent were recruited consecutively. We excluded patients with urinary tract infection and patients who were unable to provide information.

\section{Operational definitions}

Microalbuminuria was defined as Albumin to Creatinine Ratio (ACR) between 30 and $299 \mathrm{mg} / \mathrm{g}$

Type1 DM: This referred to patients who required insulin and were depending on insulin for glucose control since diagnosis.

Type 2 DM: Patients were classified as having type 2 diabetes mellitus if they required oral hypoglycemic agents or usage of combination of insulin and the oral hypoglycemic agents for glucose control.

\section{Classification of physical activity}

At work (8 hours of the day for 5 days per week):

1. Sedentary: mainly sedentary (sitting e.g. reading, working with computer)

2. Mild: predominantly walking on one level, standing, no heavy lifting

3. Moderate: mainly climbing stairs, peasantry activity

4. Strenuous: heavy physical labour e.g. lifting heavy objects

\section{During leisure (3 hours per day for at least 4 days of the week):}

1. Sedentary: sitting e.g. reading, discussions, watching television, social media, video games

2. Mild: minimal effort e.g. walking $<1 \mathrm{kmm}$, light sport, light gardening

3. Moderate: (e.g. walking $>1 \mathrm{~km}$, bicycle riding, golf at least 4 hours per week)

4. Strenuous : ( heart beats rapidly e.g. running/jogging, football, basketball, rugby, vigorous swimming)

\section{Study setting}

The study was carried out in the diabetic out-patient clinic, the medical endocrine ward and the medical emergency ward of Mulago National referral Hospital. Mulago is a National Referral Hospital in Uganda and Teaching Hospital for Makerere University with a bed capacity of 1500. Mulago Hospital receives referrals from all parts of the country including referrals from neighboring countries like Southern Sudan, the Democratic Republic of Congo, Rwanda among others. The study population is representative of the Ugandan diabetic population.

\section{Sample size estimation}

Using prevalence of $17 \%$ for microalbuminuria among 
diabetic patients as determined by Son $\mathrm{MK}$ et $\mathrm{al}^{1}$, a sample size of 180 was estimated using the Kish Leslie (1965) formula.

$\mathrm{N}=\mathrm{Z} 2 \mathrm{P}(1-\mathrm{P})$

$\mathrm{D} 2$

$\mathrm{N}=$ Sample size 180

$Z=1.96$, the normal value corresponding to the $95 \%$ confidence interval

$\mathrm{P}=0.17$, prevalence from the above study, $\mathrm{D}=0.05$, Acceptance error.

However data from 5 participants was not included because it was incomplete. Therefore we analyzed data from 175 participants.

\section{Clinical assessment}

We took a focused history and performed a specific physical exam to determine the biophysical measurements. Information gathered was entered into a pre-tested questionnaire. We assessed the following factors: patients' demographic data, history of hypertension, age, physical exercise, marital status, date of diagnosis of DM, drug history, occupation, education level, and Last Normal Menstrual Period (LNMP).

Weight was measured using a Secco weighing scale to the nearest $\mathrm{Kg}$, height was measured in meters using a non-stretchable tape and these were used to compute Body Mass Index (BMI). Waist and hip circumferences were measured and waist to hip ratios determined for all patients.

Glycated haemoglobin (HbA1C) was measured by automated high performance liquid chromatography. Other investigations included urinalysis and Microalbuminuria using ACR.

Echocardiography parameters were acquired using a commercially available machine, Phillips HD11XE (Eindhoven, The Netherlands) with 2-D, MMode and Doppler capabilities was used according to the American Society of Echocardiography ${ }^{21}$.

All equipment used were calibrated to avoid measurement bias.

\section{Assessment of microalbuminuria}

We explained to participants the procedure for collecting a mid-stream urine sample. Each participant was given two urine containers and instructed to provide 2 separate samples of mid-stream urine each measuring $10 \mathrm{ml}$. One of the containers was sterile and the sterile sample was used for urinalysis including urine microscopy. We excluded participants who were found to have urinary tract infection and we started them on antibiotics. The second container collected a spot urine sample for measurement of urine albumin to creatinine ratio (ACR). Microalbuminuria was defined as ACR between 30 and $299 \mathrm{mg} / \mathrm{g}$.

\section{Blood pressure measurement}

Blood pressure was measured using a mercury sphygmomanometer and an average of the 2 readings was used in the analysis.

We instructed each participant to sit on a chair with both feet resting on the floor uncrossed and rest for $5 \mathrm{~min}$ utes before taking the 2 blood pressure readings. The two blood pressure readings were recorded 5 minutes apart using a standard manual dekametaccoson MK3 mercury sphygmomanometer.

The patient exposed the arm from which blood pressure was to be measured and rested it on a table at the level of the heart. A blood pressure cuff (with a bladder length $>80 \%$ of the arm circumference) was placed $2 \mathrm{~cm}$ above the antecubital fossa. We inflated the cuff while feeling for the patient's radial pulse.

The estimate of the systolic blood pressure was obtained by inflating the cuff $30 \mathrm{mmHg}$ above the point of disappearance of the radial pulse. We then placed the diaphragm of the stethoscope on the antecubital fossa and the cuff deflated at $2 \mathrm{mmHg}$ per second while listening for korotkoff sounds.

Korotkoff sounds 1 and 2 represented systolic and diastolic blood pressures respectively. For cases where Korotkoff sounds remained audible despite complete deflation of the cuff, abrupt muffling of the sounds was used to denote diastolic blood pressure. We recorded the average of the 2 blood pressure readings. Participants were declared hypertensive if they; were on anti-hypertensive medication, had history of hypertension and/or evidence of hypertension (blood pressure $\geq 140 / 90 \mathrm{mmHg}$ ).

\section{Ethical approval}

Institutional consent was sought from the department of Medicine Makerere University, Mulago National Referral Hospital and School of Medicine Research and Ethics 
Committee (SOMREC) of Makerere University College of Health Sciences. All study participants provided written informed consent for involvement in the study. Enrolment was totally free and voluntary and participants were free to withdraw at any time without any consequences to them. The patients' records/information was anonymized and de-identified prior to analysis.

\section{Data management and analysis}

Data was double entered in a database developed with EPIDATA version 3.1, validated and inconsistences cleared then exported to STATA 13 for analysis. Continuous data was summarized using measures of central tendency while categorical data was summarized as frequencies and percentages and presented in tables. Prevalence was presented as percentages with their confidence intervals. Comparisons were made using the student t-test for the continuous data and xhi-square or fisher's exact test for the categorical data.

The outcome was dichotomized as having microalbuminuria or not then logistic regression was used to determine the association between the predictors and microalbuminuria. This was presented as Odds ratio (OR) and their 95\% confidence interval (CI). Only factors with $\mathrm{P}$ - value $<0.2$ at bivariate analysis were considered for multivariate analysis. Multivariate logistic regression was performed; interaction was assessed for using the Chunk test. Confounding was assessed for using a 10\% difference between the crude and adjusted models. Significance was at $\mathrm{p}$ value of 0.05 and less.

\section{Results}

Characteristics of newly diagnosed diabetic patients at Mulago National referral hospital who participated in the study.

This study recruited 175 newly diagnosed diabetic patients between June 2014 and January 2015. Of these, $90(51.4 \%)$ were males. The mean age of all the participants was $46 \pm 15$ years. Majority of patients had type 2 DM, $140(80.0 \%)$ and the rest had type 1 DM, 35 (20.0\%). The mean $\mathrm{HbA} 1 \mathrm{C}$ was $13.9 \pm 5.3 \%$. Mean duration of diabetes was 2 months. (Table 1 and table 2).

Table 1. Social demographic characteristics of newly diagnosed diabetic patients at Mulago National referral hospital who participated in the study. $(N=175)$.

\begin{tabular}{|c|c|c|c|c|}
\hline \multicolumn{2}{|c|}{ Characteristic } & Total $(\mathbf{N})$ & Microalbuminuric & Normoalbuminuric \\
\hline \multirow[t]{2}{*}{ Age } & $<40$ years & $50(28.5)$ & $25(50.0)$ & $25(50.0)$ \\
\hline & 40 years and above & $125(71.5)$ & $58(46.4)$ & $67(53.6)$ \\
\hline \multirow[t]{2}{*}{ Gender } & Male & $90(51.4)$ & $46(31.1)$ & $44(48.9)$ \\
\hline & Female & $85(48.6)$ & $37(43.5)$ & $48(56.5)$ \\
\hline \multirow[t]{2}{*}{ Employment } & Employed & $66(37.7)$ & $31(47.0)$ & $35(53.0)$ \\
\hline & Unemployed & $108(62.3)$ & $51(47.2)$ & $57(52.8)$ \\
\hline \multirow[t]{2}{*}{ Pregnancy } & Yes & $6(6.3)$ & $5(83.3)$ & $1(16.7)$ \\
\hline & No & $90(93.7)$ & $38(42.2)$ & $52(57.8)$ \\
\hline \multirow[t]{4}{*}{ Education } & None & $14(8.5)$ & $7(50.0)$ & $7(50.0)$ \\
\hline & Primary & $71(6.6)$ & $33(46.5)$ & $38(53.5)$ \\
\hline & Secondary & $64(36.6)$ & $29(45.3)$ & $35(54.7)$ \\
\hline & Tertiary & $26(14.9)$ & $14(53.9)$ & $12(46.2)$ \\
\hline \multirow[t]{3}{*}{ Marital status } & Never married & $26(14.9)$ & $14(53.9)$ & $12(46.1)$ \\
\hline & Currently married & $104(59.4)$ & $48(46.1)$ & $56(53.9)$ \\
\hline & No longer married & $45(25.7)$ & $21(46.7)$ & $24(53.3)$ \\
\hline
\end{tabular}


Table 2: Characteristics of newly diagnosed diabetic patients at Mulago National referral hospital who participated in the study. $(N=175)$.

\begin{tabular}{|c|c|c|c|c|}
\hline \multicolumn{2}{|c|}{ Characteristic } & Total (\%) & $\begin{array}{c}\text { Micro-albuminuric } \\
\text { N }(\%)\end{array}$ & $\begin{array}{c}\text { Normo-albuminuric } \\
\mathbf{N}(\%)\end{array}$ \\
\hline \multirow{4}{*}{$\begin{array}{l}\text { Physical activity at } \\
\text { work }\end{array}$} & Sedentary & $17(9.8)$ & $11(64.7)$ & $6(35.3)$ \\
\hline & Mild & $48(27.7)$ & $23(47.9)$ & $25(52.1)$ \\
\hline & Moderate & $71(41.0)$ & $33(46.5)$ & $38(53.5)$ \\
\hline & Strenuous & $37(21.4)$ & $15(40.5)$ & $22(59.5)$ \\
\hline \multirow{4}{*}{$\begin{array}{l}\text { Physical activity at } \\
\text { leisure } \\
\text { DM type }\end{array}$} & Sedentary & $123(70.3)$ & $60(48.8)$ & $63(51.2)$ \\
\hline & Moderate & $52(29.7)$ & $23(44.2)$ & $29(55.8)$ \\
\hline & Type 1 & $35(20.0)$ & $19(54.3)$ & $16(45.7)$ \\
\hline & Type 2 & $140(80.0)$ & $64(45.7)$ & $76(54.3)$ \\
\hline \multirow[t]{2}{*}{ Hypertension } & Hypertensive & $108(61.7)$ & $47(43.5)$ & $61(56.5)$ \\
\hline & Normotensive & $67(38.3)$ & $36(53.7)$ & $31(46.3)$ \\
\hline \multirow[t]{4}{*}{$\mathrm{BMI}\left(\mathrm{kg} / \mathrm{m}^{2}\right)$} & Underweight $(<19 \cdot 0)$ & $33(18.9)$ & $23(69.7)$ & $10(30.3)$ \\
\hline & $\begin{array}{l}\text { Normal weight }(19 \cdot 0 \text { - } \\
<25 \cdot 0)\end{array}$ & $70(40.0)$ & $35(50.0)$ & $35(50.0)$ \\
\hline & $\begin{array}{l}\text { Overweight } \\
(25 \cdot 0-<30 \cdot 0)\end{array}$ & $42(24.0)$ & $13(31.0)$ & $29(69.0)$ \\
\hline & Obesity $(\geq 30 \cdot 0)$ & $30(17.1)$ & $12(40.0)$ & $18(60.0)$ \\
\hline \multirow{4}{*}{$\begin{array}{l}\text { Waist hip } \\
\text { ratio } \\
\mathrm{HbA} 1 \mathrm{C} \%\end{array}$} & Normal & $123(70.3)$ & $61(49.6)$ & $62(50.4)$ \\
\hline & Abnormal & $52(29.7)$ & $30(57.7)$ & $22(42.3)$ \\
\hline & $<7 \%$ & $14(8.1)$ & $3(21.4)$ & $11(78.6)$ \\
\hline & $>7 \%$ & $158(91.9)$ & $79(50.0)$ & $79(50.0)$ \\
\hline \multirow[t]{3}{*}{ Drugs } & ACEI/ARBs & $9(5.1)$ & $4(44.4)$ & $5(55.6)$ \\
\hline & $\mathrm{CCB}$ & $12(6.9)$ & $3(25.0)$ & $9(75.0)$ \\
\hline & Beta blockers & $4(2.3)$ & $2(50.0)$ & $2(50.0)$ \\
\hline \multirow[t]{2}{*}{ Ejection fraction $\%$} & $>50 \%$ & $139(79.5)$ & $65(46.8)$ & $74(53.2)$ \\
\hline & $<50 \%$ & $36(20.5)$ & $18(50.0)$ & $18(50.0)$ \\
\hline \multirow[t]{2}{*}{ LVH } & Present & $98(56.0)$ & $42(42.9)$ & $56(57.1)$ \\
\hline & Absent & $77(44.0)$ & $41(53.3)$ & $36(46.7)$ \\
\hline \multirow[t]{2}{*}{ Diastolic function } & Normal & $83(47.4)$ & $43(51.8)$ & $40(48.2)$ \\
\hline & Impaired & $92(52.6)$ & $40(43.5)$ & $52(56.5)$ \\
\hline \multirow[t]{2}{*}{ Wall motion } & Normal & $170(97.1)$ & $81(47.6)$ & $89(52.4)$ \\
\hline & Abnormal & $5(2.9)$ & $2(40.0)$ & $3(60.0)$ \\
\hline
\end{tabular}

\section{Prevalence of microalbuminuria}

Prevalence of microalbuminuria was $47.4 \%$ (95\% CI: $40.0 \%-54.9 \%$ ) among all the patients that were assessed in the study. Among these patients, females had a higher prevalence of microalbuminuria, of $43.5 \%$ compared to males with $31.1 \%$. Type $1 \mathrm{DM}$ patients had a higher prevalence of microalbuminuria 19(54.3\%) compared to 64( 45.7\%) among type 2 DM. Patients with central obesity as measured by waist hip ratio had a higher prevalence of Microalbuminuria of $57.7 \%$ compared to those without central obesity whose prevalence was $49.6 \%$. Table 2 .

\section{Factors associated with microalbuminuria.}

In bivariate analysis, the factors associated with microalbuminuria included: being overweight and obesity. (Refer to Table 3). 
After adjusting for patients' sex, age, hypertension, anti-hypertensive drugs and level of $\mathrm{HbA} 1 \mathrm{C}$, the only significant factor associated with microalbuminuria was pregnancy (OR7.74[95\%CI.1.01-76.47] $\mathrm{P}=0.050$ ) while mild and moderate physical activity at work were in- versely associated with microalbuminuria respectively (OR0.08[95\%CI0.01-0.95] P=0.046) and (OR0.07[95\%CI0.01-0.77] $\mathrm{P}=0.030)$. Overweight and obesity has no significant association with microalbuminuria. (Refer to Table 3).

Table 3: Logistic regression for factors associated with microalbuminuria among newly diagnosed diabetic patients at Mulago hospital.

\begin{tabular}{|c|c|c|c|c|c|c|c|}
\hline \multirow[t]{2}{*}{ Factor } & & \multicolumn{2}{|c|}{ Microalbuminuria } & \multirow[t]{2}{*}{ Crude OR(CI). } & \multirow[t]{2}{*}{ P-value } & \multirow[t]{2}{*}{ Adjusted OR } & \multirow[t]{2}{*}{ P-value } \\
\hline & & $\begin{array}{l}\text { Absent } \\
\text { No(\%) }\end{array}$ & $\begin{array}{l}\text { Present } \\
\text { No(\%) }\end{array}$ & & & & \\
\hline \multirow[t]{2}{*}{ Sex } & Male & $44(48.9)$ & $46(51.1)$ & 1.00 & & 1.00 & \\
\hline & Female & $48(56.5)$ & $37(43.5)$ & $0.74(0.41-1.34)$ & 0.316 & $1.21(0.26-5.70)$ & 0.802 \\
\hline \multirow[t]{2}{*}{ Age } & $<40$ years & $25(50.0)$ & $25(50.20$ & 1.00 & & 1.00 & \\
\hline & 40 and above & $67(53.6)$ & $58(46.4)$ & $0.87(0.45-1.67)$ & 0.667 & $1.11(0.24-5.16)$ & 0.891 \\
\hline \multirow[t]{2}{*}{ Pregnancy } & No & $52(57.8)$ & $38(42.2)$ & 1.00 & & 1.00 & \\
\hline & Yes & $1(16.7)$ & $5(83.3)$ & $6.84(0.77-60.98)$ & 0.085 & $\begin{array}{l}7.74(1.01- \\
76.47)\end{array}$ & 0.050 \\
\hline \multirow{4}{*}{$\begin{array}{l}\text { Physical activity } \\
\text { at work }\end{array}$} & Sedentary & $6(35.3)$ & $11(64.7)$ & 1.00 & & 1.00 & \\
\hline & Mild & $25(52.1)$ & $23(47.9)$ & $0.47(0.16-1.42)$ & 0.183 & $0.08(0.01-0.95)$ & 0.046 \\
\hline & Moderate & $38(53.5)$ & $33(46.5)$ & $0.37(0.11-1.22)$ & 0.104 & $0.07(0.01-0.77)$ & 0.030 \\
\hline & Strenuous & $22(59.5)$ & $15(40.5)$ & $0.55(0.03-1.37)$ & 0.687 & $0.19(0.13-2.73)$ & 0.223 \\
\hline \multirow{4}{*}{$\begin{array}{l}\text { Physical activity } \\
\text { at leisure } \\
\text { HbA1C }\end{array}$} & Sedentary & $63(51.2)$ & $60(48.8)$ & 1.00 & & & \\
\hline & Moderate & $29(55.8)$ & $23(44.2)$ & $0.83(0.43-1.59)$ & 0.582 & & \\
\hline & Normal & $11(78.6)$ & $3(21.4)$ & 1.00 & & 1.00 & \\
\hline & Abnormal & $79(50.0)$ & $79(50.0)$ & $3.67(0.99-13.65)$ & 0.053 & $2.28(0.32-16.16)$ & 0.408 \\
\hline \multirow[t]{2}{*}{ Hypertension } & Normotensive & $31(46.3)$ & $36(53.7)$ & 1.00 & & 1.00 & \\
\hline & Hypertensive & $61(56.5)$ & $47(43.5)$ & $0.66(0.36-1.22)$ & 0.189 & $2.38(0.66-8.57)$ & 0.183 \\
\hline \multirow[t]{3}{*}{ Drugs } & ACEI/ARBs & $5(55.6)$ & $4(44.4)$ & $0.88(0.23-3.40)$ & 0.854 & & \\
\hline & $\mathrm{CCBs}$ & $9(75.0)$ & $3(25.0)$ & $0.35(0.90-1.32)$ & 0.121 & $0.38(0.06-2.27)$ & 0.289 \\
\hline & Beta blockers & $2(50.0)$ & $2(50.0)$ & $1.11(0.15-8.07)$ & 0.917 & & \\
\hline \multirow[t]{2}{*}{ DM type } & Type 1 & $16(45.7)$ & $19(54.3)$ & 1.00 & & 1.00 & \\
\hline & Type 2 & $76(54.3)$ & $64(45.7)$ & $0.71(0.34-1.49)$ & 0.365 & $0.52(0.08-3.56)$ & 0.507 \\
\hline \multirow[t]{3}{*}{ BMI } & Normal weight & $45(43.7)$ & $58(56.3)$ & 1.00 & & 1.00 & \\
\hline & Overwt \& & $47(65.3)$ & $25(34.7)$ & $0.41(0.22-0.77)$ & 0.005 & $0.37(0.12-1.13)$ & 0.082 \\
\hline & Obesity & & & & & & \\
\hline \multirow[t]{2}{*}{ Ejection fraction } & $>50 \%$ & $74(53.2)$ & $65(46.8)$ & 1.00 & & & \\
\hline & $<50 \%$ & $18(50.0)$ & $18(50.0)$ & $1.14(0.55-2.37)$ & 0.729 & & \\
\hline \multirow[t]{2}{*}{ LVH } & Absent & $36(46.7)$ & $41(53.3)$ & 1.00 & & & \\
\hline & Present & $56(57.1)$ & $42(42.9)$ & $0.66(0.36-1.20)$ & 0.173 & & \\
\hline Odds Ratio & $N$ Number & $\% P e$ & entage & & & & \\
\hline Confidence Inter & MI Body Mass I & $D M I$ & abetes $\mathrm{Mel}$ & H Left Ventricul & Hypertroph & & \\
\hline
\end{tabular}

\section{Discussion}

In this study, we found a high prevalence of microalbuminuria among diabetic patients who were newly diagnosed with the disease. Approximately half of all participants had significant microalbuminuria (47.4\%). Prevalence of microalbuminuria among type 1 diabetics was 54.3 while type 2 diabetic patients had $45.7 \%$. The prevalence is rather higher than what Mi Kyung et al found in a prospective study of patients with type $1 \mathrm{DM}$. In their population, type 1 diabetic patients had prevalence of Microalbuminuria of $17 \%$. Mi Kyung et al as- sessed adolescents with median age of 18.9 years while our population had a mean age of $46 \pm 15$ years, the effect of age could explain the difference. Alleyn in a prospective cohort study noted that approximately one third of persons with Type $1 \mathrm{DM}$ develop microalbuminuria ${ }^{6,22,23}$. The prevalence we found was slightly higher than Alleyn's estimate possibly because of advanced age for our patient population compared to their population of adolescents.

Among type 2 diabetic patients, we found a prevalence of $45.7 \%$ which is comparable to findings by Mi Kyung et 
al, they had a prevalence of microalbuminuria of $44.4 \%$ among type 2 diabetic patients ${ }^{1}$. This high prevalence may be due to a period of latency for patients with type $2 \mathrm{DM}$ before diagnosis. Chowta et al in a cross-sectional study reports that in type- 2 diabetics, microalbuminuria ranges from $8-47 \% 0^{12,24,25}$. These findings are in agreement with our findings for patients with type 2 DM. Three other cross-sectional studies among type 2 diabetic patients in Nepal and Bangladesh consistently reported a high prevalence of microalbuminuria ranging from $30-47 \% 0^{26-28}$. The high prevalence of microalbuminuria among type 2 diabetic patients cannot be over emphasized in Uganda, a country with majority of diabetic patients having type 2 DM. Jean Jacques added more evidence to the fact that approximately one third to half of patients with DM develops renal complications ${ }^{14,29}$.

In our patient population, age had no effect on the degree of MA and Lampropoulou reached a similar conclusion in their study where age showed just a weak correlation with $\mathrm{MA}^{16,30}$. Although microalbuminuria was more common in participants 40 years and older in our study, this is predictable because age and diabetes duration for more than 10 years are well known risk factors for the development of diabetic nephropathy ${ }^{16}$.

We found the prevalence of microalbuminuria to be more common among females and Okpere et al came to a similar conclusion in their study of Nigerian adolescents. Similarly patients who had central obesity in our study had a higher prevalence of MA compared to those without central obesity, Okpere reports similar findings 5 .

The prevalence of microalbuminuria we found of $47.4 \%$ is 3 times higher than that of the general population which is reported to be $10-15 \%{ }^{5}$. However most of this evidence is from the developed world and in Africa, there is paucity of data on the prevalence of microalbuminuria both in the general population and among diabetics ${ }^{5}$.

Among diabetic patients, microalbuminuria predicts the development of overt diabetic nephropathy ${ }^{5}$. Therefore a high prevalence we found predicts a great burden of renal disease for our patient population if no interventions are done.

In our study, microalbuminuria had no significant association with BMI and this is in keeping with finding by Chowta et al who found that there is no effect of BMI and sex on the prevalence of microalbuminuria ${ }^{12}$. Likewise sex had no significant association with microalbuminuria in this study. Patients who exercised mildly and moderately during work were less likely to develop microalbuminuria. This makes exercise a possible protective factor against microalbuminuria among diabetics.

Pregnant patients in our study were seven times more likely to have significant microalbuminuria compared with those who were not pregnant. The possible reason could be the pregnancy associated protein loss and likely hypertension in pregnancy. These are potential confounders in our study.

Physical activity at work was inversely associated with microalbuminuria in this study. In SSA, this is one of the first studies to describe a relationship between microalbuminuria and physical activity at work. To better understand the long term effect of physical activity at work on kidney function among diabetic patients in Africa, there is need for longitudinal studies.

We found no association of microalbuminuria with glycemic control as measured by HbA1C. This is different from findings by Alleyn. In their study, microalbuminuria occurred in association with poor glycemic control and elevated blood pressure ${ }^{6}$. In addition hypertension had no significant association with microalbuminuria in this study which is in contrast with findings by Alleyn. The differences could be due to the differences in age for the two populations. Alleyn assessed a predominantly young population of type 1 diabetics while we assessed a population with mean age of $46 \pm 15$ years. In addition Alleyn followed up their cohort for 2 years yet ours was a cross sectional study 6 .

Gender was not associated with microalbuminuria in this study although the prevalence of microalbuminuria was higher among females than males; this difference was not statistically significant. Chowta et al reported similar findings: There was no correlation between gender and microalbuminuria in type- 2 diabetes mellitus ${ }^{12,31}$.

Studies in the western world show a positive correlation between degree of microalbuminuria, BMI and blood pressure $^{12}$; these findings are different from evidence generated in our study where there is no association of microalbuminuria with hypertension and BMI. Asadujjaman et al reached a similar conclusion is a cross-sectional 
study in Bangladesh which found no association between microalbuminuria and BMI among diabetic patients ${ }^{28}$. However, Khadka et al in a cross sectional study among type 2 diabetic patients in Nepal found hypertension to be associated with microalbuminuria ${ }^{26}$.

Evidence shows that DN is more frequent among patients in Africa as compared to those in the developed world. Possible reasons include delay in diagnosis, limited screening/diagnostic resources, poor control of blood sugar and blood pressure and inadequate treatment at an early stage $e^{14,19,20}$. However, evidence on the burden of kidney diseases in people with diabetes in Africa remains very patchy ${ }^{14}$. A meta-analysis in sub-Saharan Africa has found the prevalence of DN to be $36 \%{ }^{32}$, while in China $\mathrm{DN}$ is only present in $8 \%$ of diabetic patients ${ }^{33}$.

We recognize that the lack of a non-diabetic control population is a limitation of our study; however, this study was not designed to determine the effect of diabetes on the kidney, but rather to explore the magnitude of subclinical microalbuminuria among newly diagnosed diabetic patients in the SSA context, including the factors associated with microalbuminuria.

The short duration of the study could have obscured seasonal variability. This was due to limitations in logistics: however newly diagnosed diabetic patients were recruited consecutively over a seven months period.

We did not analyze data from 5 participants because it was incomplete. This limitation could have affected the power of the study.

\section{Conclusion}

Prevalence of microalbuminuria was high in this patient population of newly diagnosed diabetes mellitus. Pregnancy was positively associated with significant microalbuminuria while physical activity at work was inversely associated with microalbuminuria. Early detection and management of microalbuminuria may help in preventing deterioration in renal function and development of overt diabetic nephropathy and progression to ESRD. Physical activity at work may have a protective effect against microalbuminuria and $\mathrm{DN}$; longitudinal studies on this subject are needed.

\section{Source of funding}

Research reported in this manuscript was supported by the Fogarty International Center of the National Institutes of Health under award number R24TW008861. Dr
Martin Muddu was also supported by the Fogarty International Center and the National Heart, Lung, and Blood Institute (NHLBI) at the National Institutes of Health under the Global Health Equity Scholars Consortium at Yale University (D43TW010540). The content is solely the responsibility of the authors and does not necessarily represent the official views of the National Institutes of Health.

\section{Acknowledgement}

The authors are grateful to the following persons for their invaluable support: Prof. Nelson Sewankambo, Prof. Moses R. Kamya, the staff of ward $4 \mathrm{~B}$ endocrine, diabetic clinic, the echocardiography and clinical laboratory of Mulago hospital.

\section{Abbreviations: \\ ACR Albumin to Creatinine Ratio \\ ESRD End stage renal disease \\ DM Diabetes mellitus \\ CVD Cardiovascular Diseases \\ LVH Left Ventricular Hypertrophy \\ DN Diabetic nephropathy \\ BMI Body Mass Index \\ SSA sub-Saharan Africa. \\ Competing interests}

The authors declare that they have no competing interests.

\section{Authors' contributions}

MM, MCK, SI, ME, made significant contributions to the conception and design of the study. SK made significant contributions on data analysis and participated significantly in developing the manuscript. MF participated in the process of collecting data for this study. MM drafted the initial manuscript and all the authors provided critical revision and gave final approval for the version to be published.

\section{References}

1. Son MK, Yoo HY, Kwak BO, et al. Regression and progression of microalbuminuria in adolescents with childhood onset diabetes mellitus. Annals of Pediatric Endocrinology \& Metabolism. 2015;20:13-20 PubMed.

2. Allen KV, Walker JD. Microalbuminuria and mortality in long-duration type 1 diabetes. Diabetes Care. 2003;3(26):2389-91. PubMed. 
3. Gerstein HC, Mann JF, Yi Q, et al. Albuminuria and risk of cardiovascular events, death, and heart failure in diabetic and nondiabetic individuals. JAMA. 2001;286:4216. PubMed.

4. Chen H, Zheng Z, Huang Y, et al. A Microalbuminuria Threshold to Predict the Risk for the Development of Diabetic Retinopathy in Type 2 Diabetes Mellitus Patients. PLoS One. 2012; 7 (5):36718 PubMed.

5. Okpere AN, Anochie IC, Eke FU. Prevalence of Microalbuminuria among secondary school children. African Health Sciences. 2012;12(2).

6. Alleyn CR, Volkening LK, Wolfson J, Rodriguez-Ventura A, Wood JR, Laffel LM. Occurrence of microalbuminuria in young people with Type 1 diabetes: importance of age and diabetes duration. Diabet Med. 2010 27(5):5327.

7. Donaghue KC, Fairchild JM, Chan A, Hing SJ, Howard NJ, Silink M. Diabetes complications screening in 937 children and adolescents. J Pediatr Endocrinol Metab. 1999;12:18 -192.

8. Correa-Rotter R, Naicker S, Katz IJ, et al. Demographic and epidemiologic transition in the developing world. Role of albuminuria in the early diagnosis and prevention of renal and cardiovascular disease. Kidney Int. 2004;92 (66):32-7.

9. De Jong PE, Brenner BM. From secondary to primary prevention of progressive renal disease: the case for screening for albuminuria. Kidney Int. 2004;92(66):109-18. 10. Ruggenenti P, Perna A, Gherardi G, et al. Renoproctective properties of ACE inhibition in non-diabetic nephropathies with nonnephrotic proteinuria. Lancet. 1999;354:359-64. PubMed.

11. Mogensen CE, Kerne WF, Bennett PH, et al. Prevention of diabetic renal disease with special reference to microalbuminuria. Lancet. 1995;346:1080-4. PubMed.

12. Chowta NK, Pant P, Chowta MN. Microalbuminuria in diabetes mellitus: Association with age, sex, weight, and creatinine clearance. Indian J Nephrol. 2009;19(2):536. PubMed.

13. Perkins BA, Ficociello LH, Silva KH, Finkelstein DM, Warram JH, Krolewski AS. Regression of microalbuminuria in type 1 diabetes. N Engl J Med. 2003;348:2285-93 PubMed.

14. Noubiap JJ, Naidoo J, Kengne AP. Diabetic nephropathy in Africa: A systematic review. World J Diabetese. 2015 10(6):759-73.
15. Harjutsalo V, GroopPH. Epidemiology and risk factors for diabetic kidney disease. Adv Chronic Kidney Dis. 2014;21:260-6 PubMed.

16. Lampropoulou IT, Stangou M, Papagianni A, Didangelos T, Iliadis F, Efstratiadis G. TNF-a and Microalbuminuria in Patients with Type 2 Diabetes Mellitus. Journal of Diabetes Research. 2014; 2014.

17. Molitch ME, Defronzo RA, Franz MJ, Keane WF. Nephropathy in diabetes, Diabetes Care. 2004;27(1): s79-s83. PubMed.

18. Hovind P, Tarnow L, Rossing P, et al. Predictors for the development of microalbuminuria and macroalbuminuria in patients with type 1 diabetes: inception cohort study. BMJ. 2004;328:1105.

19. Mbanya JC, Motala AA, Sobngwi E, Assah FK, Enoru ST. Diabetes in sub-Saharan Africa. Lancet. 2010;375:2254-66.

20. Kengne AP, Echouffo-Tcheugui JB, Sobngwi E, Mbanya JC. New insights on diabetes mellitus and obesity in Africa-part 1: prevalence, pathogenesis and comorbidities. Heart. 2013;99:979-83. PubMed.

21. Lang RM, Bierig M, Devereux RB, et al. Recommendations for chamber quantification: A report fromthe American Society of Echocardiography's Guidelines and Standards Committee and the Chamber Quantification Writing Group, developed in conjunction with the European Association of Echocardiography, a branch of the European Society of Cardiology. Journal of the American Society of Echocardiography. 2005;18:1440-63.

22. Hovind P, Tarnow L, Rossing P, et al. Predictors for the development of microalbuminuria and macroalbuminuria in patients with type 1 diabetes: inception cohort study. BMJ. 2004;328:1105.

23. Krolewski AS, Warram JH, Christlieb AR, Busick EJ, Kahn CR. The changing natural history of nephropathy in type I diabetes. Am J Med. 1985;78:785-94 PubMed.

24. Parving HH, Gall MA, Skøtt P, et al. Prevalence and causes of microalbuminuria in patients with non-insulin dependent diabetic patients. Kidney Int. 1992;41:758-62.

25. Taneja V, Sircar S, Kansra U, Lamba IM. Microalbuminuria in normotensive non insulin dependent diabetic subjects-associations and predictions. J Diabetes Assoc Ind. 1997;37:30-6.

26. Khadka B, Tiwari ML, Timalsina B, Risal P, Gupta S, Acharya D. Prevalence and Factors Associated with Microalbuminuria among Type 2 Diabetic Patients: A Hospital Based Study. Age (years). 2018;50(107):26.8. 
27. Kajingulu FM, Lepira FB, Mbutiwi FI, et al. Albuminuria status and patterns of dyslipidemia among type 2 diabetes black patients managed at a tertiary health-care hospital: A Post hoc analysis. Saudi Journal of Kidney Diseases and Transplantation. 2018;29(3):649.

28. Asadujjaman M, Kashem A, Chowdhury AA, et al. Prevalence of Microalbuminuria and Overt Proteinuria in Diabetes Mellitus and their Association with Renal Function. Mymensingh medical journal: MMJ. 2018;27(3):46774.

29. Bakris GL. Recognition, pathogenesis, and treatment of different stages of nephropathy in patients with type 2 diabetes mellitus. Mayo Clin Proc. 2011;86:444-56. PubMed 30. Molitch ME, Defronzo RA, Franz MJ, Keane WF. Nephropathy in diabetes. Diabetes Care. 2004;27(1):s79-s83. 31. Ruilope LM, Segura J. Predictors of the evolution of microalbuminuria. Hypertension. 2006;48:832-3.

32. Wagnew F, Eshetie S, Kibret GD, et al. Diabetic nephropathy and hypertension in diabetes patients of sub-Saharan countries: a systematic review and meta-analysis. BMC Research Notes. 2018;11(1):565.

33. Zhuo L, Zou G, Li W, Lu J, Ren W. Prevalence of diabetic nephropathy complicating non-diabetic renal disease among Chinese patients with type 2 diabetes mellitus. European Journal of Medical Research. 2013;18(1):4. 